\title{
Contribution of specific dietary factors to CHD in US females
}

\author{
Nga Tran* and Leila Barraj \\ Exponent, 1150 Connecticut Avenue NW, Suite 1100, Washington, DC 20036, USA
}

Submitted 19 May 2008: Accepted 29 April 2009: First published online 17 July 2009

\begin{abstract}
Objective: To estimate dietary cholesterol contribution to CHD risk among US females, relative to other dietary risk factors.

Design: A risk apportionment model was applied to apportion CHD risk shares among the lifestyle and dietary risk factors.

Setting: The model was implemented using relative risks from the Nurses' Health Study and data on CHD risk factors and consumption from the National Health and Nutrition Examination Survey 1999-2002.

Subjects: US females aged 25 years or older.

Results: On average, poor diet contributes $20 \%$ of the CHD risk relative to obesity, inactivity and smoking, of which trans fat intake contributes $2.9 \%$, dietary cholesterol $1.5 \%$ and $16 \%$ is due to low consumption of nutrients, i.e. MUFA (1.5\%), PUFA (1.7\%), marine $n$-3 fatty acids $(2.7 \%), \alpha$-linolenic acid $(1 \cdot 1 \%)$, dietary fibre $(2 \cdot 4 \%)$, vitamin $\mathrm{B}_{6}(4 \cdot 1 \%)$, vitamin $\mathrm{C}(0.5 \%)$ and folate $(1 \cdot 8 \%)$.

Conclusions: Reducing trans fat and dietary cholesterol intakes could lead to CHD reduction, but greater risk reduction may be achieved by improving intakes of heart-healthy nutrients currently deficient in US females' diets. Total diet consideration is essential in any CHD risk reduction strategy.
\end{abstract}

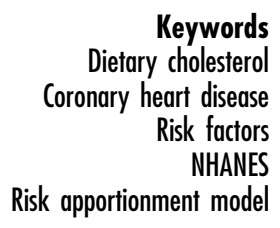

Despite the multiple risk factors including older age, male gender, genetic, race, smoking, inactivity, overweight, diet, high blood pressure, high blood cholesterol and diabetes mellitus, a major focus of CHD risk reduction has been on dietary cholesterol. However, recent epidemiological evidence has raised questions about the relationship between dietary cholesterol, plasma cholesterol levels and CHD risk $^{(1-4)}$.

The Health Professionals' Follow-up Study (HPFS) showed no association between dietary cholesterol and CHD risk among male subjects ${ }^{(2)}$. At the highest quintile of intake $(422 \mathrm{mg} / \mathrm{d})$ the relative risk (RR) was $1.03(95 \%$ CI $0 \cdot 81,1 \cdot 32)$. A non-significant association between dietary cholesterol and CHD risk was observed among females in the Nurses' Health Study (NHS). There was a slight increase in CHD risk for all quintiles of cholesterol intake $(P \text { for trend }=0 \cdot 24)^{(2)}$.

In the present paper the dietary cholesterol contribution to CHD risk among US females aged 25 years or older was derived using RR estimates from the NHS and data on intake and CHD risk factors from the National Health and Nutrition Examination Survey (NHANES) 1999-2002. A risk apportionment model ${ }^{(5)}$ was applied. The egg cholesterol share of $\mathrm{CHD}$ risk was also ascertained.

\section{Methods}

\section{Model}

A proportional weight risk apportionment model was used to calculate the contribution of risk factors to the overall CHD risk. Techniques to calculate the proportionate contribution of causal factors to a disease risk and their application to a public health setting were reviewed by Barraj et al. ${ }^{(5)}$. The 'proportional weights model' is a better model when the additivity assumption of the combined risk does not hold ${ }^{(5)}$. This model estimates assigned share $\left(\mathrm{AS}_{i}\right)$ associated with the $i$ th risk factor $\left(\mathrm{RR}_{i}\right.$ denotes the relative risk associated with the $i$ th risk factor) as:

$$
\begin{aligned}
\mathrm{AS}_{i}= & \left\{\left(\mathrm{RR}_{i}-1\right)+\sum_{j \neq i} w_{i \mid j}\left[\left(\mathrm{RR}_{i}-1\right)\left(\mathrm{RR}_{j}-1\right)\right]\right. \\
& +\sum_{\substack { j \neq i \\
\begin{subarray}{c}{k \neq i \\
k \neq j{ j \neq i \\
\begin{subarray} { c } { k \neq i \\
k \neq j } }\end{subarray}} w_{i \mid j k}\left[\left(\mathrm{RR}_{i}-1\right)\left(\mathrm{RR}_{j}-1\right)\left(\mathrm{RR}_{k}-1\right)\right] \\
& \left.+\cdots+w_{i \mid 1 \ldots n}\left[\left(\mathrm{RR}_{1}-1\right) \cdots\left(\mathrm{RR}_{n}-1\right)\right]\right\} / \mathrm{RR}_{1} \cdots \mathrm{RR}_{n}-1
\end{aligned}
$$

where

$$
w_{i \mid j}=\frac{\mathrm{RR}_{i}-1}{\mathrm{RR}_{i}+\mathrm{RR}_{j}-2},
$$




$$
w_{i \mid j k}=\frac{\mathrm{RR}_{i}-1}{\mathrm{RR}_{i}+\mathrm{RR}_{j}+\mathrm{RR}_{k}-3}
$$

and

$$
w_{i \mid 1 \ldots n}=\frac{\mathrm{RR}_{i}-1}{\sum_{j}\left(\mathrm{RR}_{j}-1\right)} .
$$

In the present study, the model was implemented as follows:

1. Stratify the US females aged 25 years or older based on their common risk attributes (diet, obesity, exercise and smoking) using NHANES 1999-2002 data ${ }^{(6)}$.

2. Within each stratum, apply the model to calculate the diet share of CHD risk, using a 'diet score', relative to obesity, exercise and smoking.

3. Within each stratum, apply an apportionment model with only the dietary factors to estimate specific dietary shares of CHD risk.

4. Within each stratum, estimate the fraction of dietary cholesterol from egg foods and apply this fraction to the dietary cholesterol share of CHD risk to calculate the egg share.

\section{Data}

The following data for the lifestyle and diet risk factors and associated RR were used to implement the model.

\section{Lifestyle factors}

The American Heart Association (AHA) has identified exercise, BMI below $25 \mathrm{~kg} / \mathrm{m}^{2}$, avoidance of smoking, moderate alcohol intake, and a diet low in trans fat and glycaemic load, high in fibre, marine $n-3$ fatty acids (FA) and folate, with a high ratio of PUFA to SFA, as important lifestyle factors to prevent CHD in women. Demographic, smoking, exercise, anthropometric and dietary data were abstracted and recoded from NHANES 1999-2002 to create the following dichotomous categories.

1. Exercise: responses to questions on vigorous or moderate physical activity over the previous month were recoded into 'heavy' and 'moderate'.

2. Smoking: participants were classified into current smokers and former/non-smokers.

3. Obesity: participants were classified into two categories, $\mathrm{BMI} \geq 25 \mathrm{~kg} / \mathrm{m}^{2}$ or $\mathrm{BMI}<25 \mathrm{~kg} / \mathrm{m}^{2}$.

4. Diet score: this was calculated using the $24 \mathrm{~h}$ food-recall data. The scoring mimicked the approach described by
Stampfer et $a l^{(7)}$ and used intakes of trans fat, cereal fibre, dietary folate, glycaemic load and PUFA:SFA ratio. A diet score was derived and categorized into quintiles. Higher quintile scores are indicative of a 'prudent' diet, e.g. low intake of trans fat, high intakes of fruits, vegetables and fibre, higher intake of chicken and fish relative to red meat and/or higher PUFA:SFA ratio ${ }^{(7)}$. Quintiles 1, 2 and 3 are categorized as poor diet and quintiles 4 and 5 as good diet.

Based on these categories, US females were stratified into groups with similar modifiable lifestyle risk factors.

\section{Intakes}

Daily nutrient and cholesterol intakes were estimated using $24 \mathrm{~h}$ consumption data for NHANES 1999-2002 and food nutrient contents from the US Department of Agriculture's (USDA) National Nutrient Database ${ }^{(8)}$. The fraction of dietary cholesterol from egg foods was determined using USDA-Environmental Protection Agency food recipes ${ }^{(9)}$. Only foods containing whole eggs or egg yolk were considered.

\section{Estimated relative risks}

A number of studies have estimated RR for CHD risk factors, but there is variability among them with respect to study size, geography, population, adjustment for confounders and design. To ensure consistency and avoid using RR for a risk factor that could have been confounded by other factors, only multivariate-adjusted RR from the NHS were used. The NHS was chosen because it is among the largest investigations of risk factors for chronic diseases in women, with long follow-up periods and carefully collected information. NHS data on the association between CHD and smoking, obesity, exercise and diet reported by Stampfer et al. ${ }^{(7)}$ were used (Table 1 ).

Estimated RR values for specific dietary factors were also derived from the NHS. A number of publications on diet factors and CHD risk from the NHS were found in the published literature. Estimated RR and intakes for most of these studies are summarized in the Appendix. The apportionment model was limited to ten dietary factors: cholesterol, marine n-3 FA, PUFA, MUFA, trans fat, $\alpha$-linolenic acid (ALA), dietary fibre, folate, vitamin $\mathrm{B}_{6}$ and vitamin $\mathrm{C}$. The rationale for this selection and the exclusion of SFA from the model are as follows.

1. SFA was not included because no association with CHD was observed in the NHS subjects $(\mathrm{RR}=1 \cdot 00$,

Table 1 Lifestyle risk factors and relative risks (RR) included in the risk apportionment model, US females aged 25 years or older

\begin{tabular}{lll}
\hline Factor & & \\
\hline Diet & Poor diet (quintile $1,2 \& 3) v$. good diet (quintile $4 \& 5)$ & $1 \cdot 46$ \\
Smoking & Current smoker $v$. former or non-smoker & $3 \cdot 33$ \\
Obesity & BMl $\geq 25 \mathrm{~kg} / \mathrm{m}^{2} v .<25 \mathrm{~kg} / \mathrm{m}^{2}$ & 1.35 \\
Exercise & Physical activity $<3.5 \mathrm{~h} /$ week $v . \geq 3.5 \mathrm{~h} /$ week & $1 \cdot 24$
\end{tabular}

*Extrapolated from Stampfer et al. (2000) ${ }^{(7)}$. 
Table 2 Dietary factors, intakes and interpolated relative risks (RR) included in the risk apportionment model ${ }^{\star}$, US females aged 25 years or older

\begin{tabular}{|c|c|c|c|c|}
\hline Dietary factor & Daily intake (NHANES 1999-2002) & Interpolated RR & $P$ & Reference \\
\hline Cholesterol & $227 \cdot 70 \mathrm{mg}$ & $1 \cdot 17$ & 0.24 & Hu et al. $(1997)^{(2)}$ \\
\hline Marine $n-3$ fatty acids & $0.07 \mathrm{~g}$ & $1 \cdot 27$ & $<0.01 t$ & Hu et al. (2002) \\
\hline$\alpha$-Linolenic acid & $0.84 \mathrm{~g}$ & $1 \cdot 14$ & 0.5 & Hu et al. $(1999)^{(15)}$ \\
\hline Trans fat & $2.49 \%$ of energy & $1 \cdot 29$ & $0.01+$ & Oh et al. $(2005)^{(10)}$ \\
\hline PUFA & $5.49 \%$ of energy & $1 \cdot 19$ & $0.004 t$ & Oh et al. $(2005)^{(10)}$ \\
\hline MUFA & $12 \cdot 66 \%$ of energy & $1 \cdot 17$ & $0 \cdot 19$ & Oh et al. $(2005)^{(10)}$ \\
\hline Dietary fibre & $14 \cdot 30 \mathrm{~g}$ & $1 \cdot 25$ & 0.07 & Wolk et al. (1999) \\
\hline Folate & $363 \cdot 70 \mu \mathrm{g}$ & $1 \cdot 20$ & $0.003 t$ & Rimm et al. $(1998)^{(13)}$ \\
\hline Vitamin $\mathrm{B}_{6}$ & $1.57 \mathrm{mg}$ & 1.38 & $0.004 t$ & Rimm et al. $(1998)^{(13)}$ \\
\hline Vitamin C & $84 \cdot 80 \mathrm{mg}$ & $1 \cdot 08$ & 0.52 & Osganian et al. $(2003)^{(16)}$ \\
\hline
\end{tabular}

NHANES, National Health and Nutrition Examination Survey.

${ }^{*}$ All outcomes: fatal + non-fatal CHD.

tStatistically significant.

$0.94,0.96,1 \cdot 04$ and 0.97 for quintiles 1 to 5 of exposure as a percentage of energy, respectively) ${ }^{(10)}$. Given that the RR for all quintiles are at unity, had SFA been included in the model, no CHD risk would be apportioned to SFA as a risk factor.

2. Although the association between dietary cholesterol and CHD is not statistically significant in the NHS, it is listed as a risk factor by the $\mathrm{AHA}^{(11)}$ and is a focus of the present study, so it was included.

3. The associations between CHD and low intake of marine $n$-3 FA ${ }^{(12)}$, PUFA ${ }^{(10)}$, folate ${ }^{(13)}$, vitamin $\mathrm{B}_{6}^{(13)}$ and dietary fibre ${ }^{(14)}$, and high intake of trans fat ${ }^{(10)}$, were statistically significant among NHS subjects and were included.

4. While not statistically significant for non-fatal CHD, the association between fatal CHD and low ALA ${ }^{(15)}$ intake was significant in the NHS and was included.

5. Although the associations between CHD and MUFA and vitamin $C$ were not statistically significant, an inverse relationship between increasing intake and $\mathrm{CHD}$ risk was observed (MUFA: RR $=1 \cdot 22,1 \cdot 15,1 \cdot 16,1 \cdot 11$ and $1 \cdot 00$ for quintiles 1 to 5 as a percentage of energy, respectively $^{(10)}$; vitamin $\mathrm{C}$ : $\mathrm{RR}=1 \cdot 16,1 \cdot 06,1 \cdot 00,0 \cdot 98$ and 1.00 for quintiles 1 to 5 of exposure, respectively ${ }^{(16)}$ ). Thus MUFA and vitamin $\mathrm{C}$ were included.

The daily intakes for these ten factors were developed using NHANES 1999-2002 data and the associated RR were extrapolated from the quintiles of intakes and RR reported in the NHS study (Table 2).

\section{Results}

\section{Diet and lifestyle factors}

The prevalence of poor diet, inactivity, obesity and smoking among US females aged 25 years or older was determined using the NHANES 1999-2002 data. Over $82 \%$ of females ( $>77$ million) have $>1$ lifestyle risk factor. The most common mutually exclusive combinations of lifestyle factors are presented in Table 3. Approximately $68 \%$ (>52 million) US females have poor diet as a risk factor, with $8 \%$ having poor diet as the only modifiable factor and $60 \%$ having combinations of $>2$ modifiable factors.

Diet contribution to CHD risk varies depending on the presence/absence of other CHD risk factors. The current study focuses on the diet and lifestyle factors while ignoring health status and non-modifiable factors such as age and genetics. When diet is examined as a whole, its share of CHD risk is $13 \%$ when obesity, inactivity and smoking risk factors are also present and 65\% when inactivity is the only other risk factor present. When diet is the only risk factor ( $8 \%$ of the females) its share of the CHD risk is $100 \%$. On average, poor diet contributes about $20 \%$ of the CHD risk among US females aged 25 years or older (Table 3).

\section{Specific dietary factors}

Of the $20 \%$ dietary share of CHD risk, relative to obesity, inactivity and smoking, current consumption of trans fat contributes $2.9 \%$, dietary cholesterol $1.5 \%$ and the remaining $16 \%$ is due to low consumption of desirable nutrients such as MUFA ( $1.5 \%)$, PUFA ( $1 \cdot 7 \%)$, marine $n$-3 FA $(2 \cdot 7 \%)$, ALA $(1 \cdot 1 \%)$, dietary fibre $(2 \cdot 4 \%)$, vitamin $\mathrm{B}_{6}$ $(4 \cdot 1 \%)$, vitamin C $(0 \cdot 5 \%)$ and folate (1.8\%; Fig. 1$)$.

Based on the NHANES 1999-2002 intake data, dietary cholesterol in $82 \%$ of US females averages $227 \cdot 7 \mathrm{mg} / \mathrm{d}$. Cholesterol intake in females with poor diet ranges from $227 \cdot 8$ to $258 \cdot 2 \mathrm{mg} / \mathrm{d}$. Those with poor diet and having $>1$ modifiable risk factor represent $68 \%$ of this group. Cholesterol intake ranges from $152 \cdot 2$ to $233.8 \mathrm{mg} / \mathrm{d}$ for females without poor diet (Table 4 ).

Among females with poor diet, cholesterol has the lowest CHD risk share $(1 \cdot 14 \%)$ when obesity, inactivity and smoking are also present, and the highest risk share $(7 \cdot 79 \%)$ when poor diet is the only risk factor (Table 4 ). Given the current cholesterol intake among US females, dietary cholesterol CHD risk share, relative to the other nine factors included in the model (trans fat, MUFA, 
Table 3 Lifestyle factors and CHD risk shares, US females aged 25 years or older

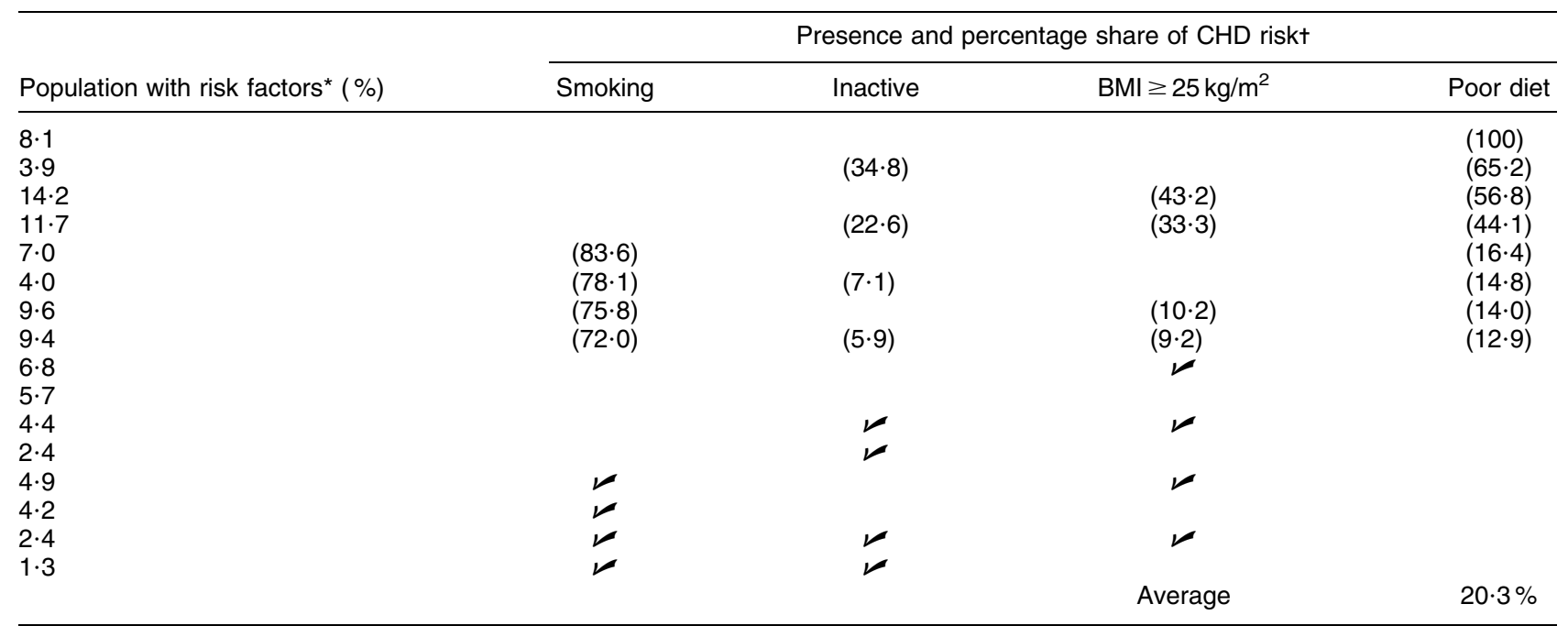

${ }^{*}$ Total weighted $n$ is 77129836 ( $~ 82 \%$ of US females in the National Health and Nutrition Examination Survey 1999-2002). $+\nu=$ present; ()$=$ CHD risk share.

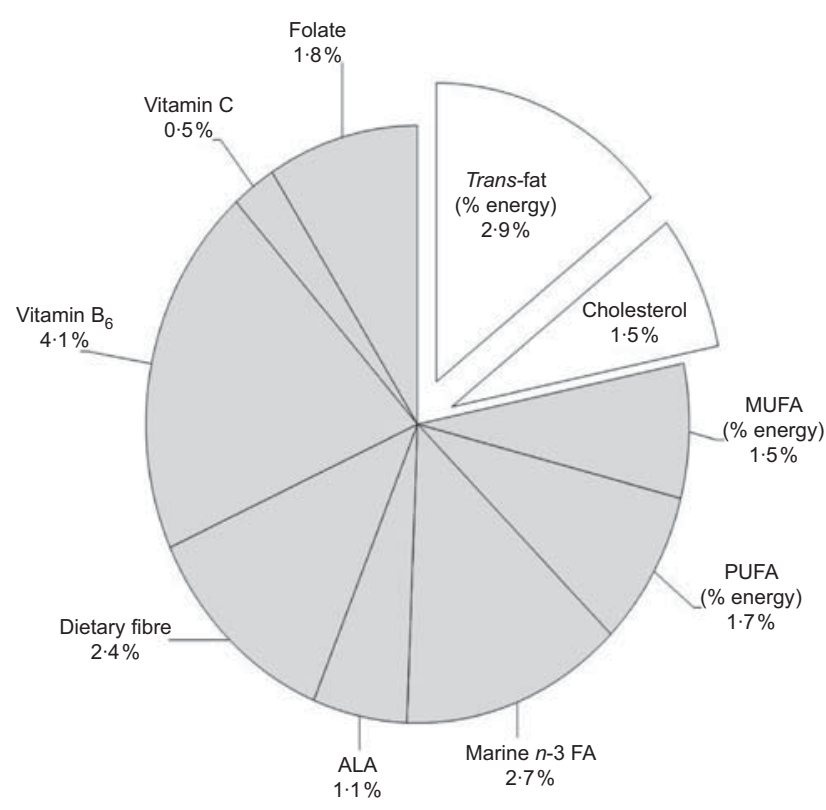

Fig. 1 Relative risk (RR) contribution of specific dietary factors among US females aged 25 years or older. Total dietary CHD risk share is $\sim 20 \%$. Specific dietary factor risk share is based on average intake and RR when compared with reference intake: cholesterol $(227.7 \mathrm{mg} / \mathrm{d}$ v. $132 \mathrm{mg} / \mathrm{d})$; marine $n-3$ fatty acids (FA; $0.07 \mathrm{~g} / \mathrm{d}$ v. $0.24 \mathrm{~g} / \mathrm{d}$ ); $\alpha$-linolenic acid (ALA; $0.838 \mathrm{~g} / \mathrm{d}$ v. $1.36 \mathrm{~g} / \mathrm{d})$; dietary fibre $(14.3 \mathrm{~g} / \mathrm{d}$ v. $22.9 \mathrm{~g} / \mathrm{d}) ;$ vitamin $B_{6}$ $(1.57 \mathrm{mg} / \mathrm{d}$ v. $4.4 \mathrm{mg} / \mathrm{d})$; vitamin C $(84 \mathrm{mg} / \mathrm{d}$ v. $209 \mathrm{mg} / \mathrm{d})$; folate $(363.7 \mu \mathrm{g} / \mathrm{d} v .696 \mu \mathrm{g} / \mathrm{d})$; trans fat $(2.5 \%$ of energy $v .1 .3 \%$ of energy); MUFA (12.7\% of energy $v .18 \%$ of energy); PUFA (5.49\% of energy v. $7 \cdot 4 \%$ of energy)

PUFA, marine n-3 FA, ALA, dietary fibre, vitamin $\mathrm{B}_{6}$, vitamin $\mathrm{C}$ and folate) and other lifestyle risk factors (obesity, inactivity, smoking), averages $1.5 \%$.

As a sensitivity analysis, the apportionment model was implemented with dietary cholesterol as the principal dietary factor (ignoring other dietary factors). In this case, dietary cholesterol was used instead of the overall diet score in the apportionment model and its contribution to $\mathrm{CHD}$ risk was assessed relative to obesity, inactivity and smoking. This analysis provides an upper-bound estimate of dietary cholesterol share of CHD risk, approximately $1.9 \%$.

Foods containing whole egg and/or egg yolk contribute 20-28\% (average 25\%) of dietary cholesterol for US females aged 25 years or older (Table 4). The egg CHD risk share when restricted to those with 'poor diet' ( $\sim 68 \%$ of the US females included in the present analysis) ranges from $0 \cdot 27 \%$ to $1 \cdot 96 \%$ (average $0 \cdot 8 \%$ ). When all females are considered the egg CHD risk share is $0 \cdot 4-0.5 \%$.

\section{Discussion}

Epidemiological studies consistently have shown a close association between CHD risk and diets high in total fat, SFA and cholesterol, and low in fibre and PUFA ${ }^{(17,18)}$. In the present study, when genetics and age were ignored, a poor diet contributed approximately $13 \%$ to $65 \%$, depending on whether smoking, obesity and inactivity were present. On average, the dietary share of CHD risk, relative to other lifestyle factors, was approximately $20 \%$ for US females aged 25 years or older.

While the relationship between overall diet and CHD is consistent, the evidence on dietary cholesterol is not always clear ${ }^{(18)}$. Recent epidemiological evidence has raised questions about whether limiting dietary cholesterol intake would lead to any significant reduction in CHD risk ${ }^{(1,3,4,19)}$. Cholesterol feeding studies demonstrating that dietary cholesterol increases both LDL and HDL cholesterol, with little change in the LDL:HDL ratio, 
Table 4 CHD risk shares for dietary and egg cholesterol, US females aged 25 years or older

\begin{tabular}{|c|c|c|c|c|c|c|c|}
\hline \multirow[b]{2}{*}{ Lifestyle factors } & \multirow[b]{2}{*}{$\begin{array}{l}\text { Population with risk } \\
\text { factors* }(\%)\end{array}$} & \multirow[b]{2}{*}{$\begin{array}{l}\text { Dietary cholesterol } \\
(\mathrm{mg} / \mathrm{d})\end{array}$} & \multicolumn{2}{|c|}{$\begin{array}{l}\text { Dietary cholesterol } \\
\text { CHD risk share (\%) }\end{array}$} & \multirow[b]{2}{*}{$\begin{array}{l}\text { Cholesterol from } \\
\text { egg foods }(\%)\end{array}$} & \multicolumn{2}{|c|}{$\begin{array}{c}\text { Egg cholesterol } \\
\mathrm{CHD} \text { risk share }(\%)\end{array}$} \\
\hline & & & & $\begin{array}{l}\text { Sensitivity } \\
\text { analysis }\end{array}$ & & & $\begin{array}{l}\text { Sensitivity } \\
\text { analysis }\end{array}$ \\
\hline Poor diet & $8 \cdot 15$ & $243 \cdot 7$ & $7 \cdot 79$ & $7 \cdot 79$ & $25 \cdot 18$ & $1 \cdot 96$ & $1 \cdot 96$ \\
\hline Poor diet \& inactive & 3.90 & $227 \cdot 8$ & $4 \cdot 74$ & $2 \cdot 99$ & $26 \cdot 73$ & $1 \cdot 27$ & $0 \cdot 80$ \\
\hline Poor diet \& overweight & $14 \cdot 16$ & 239.9 & $4 \cdot 42$ & $2 \cdot 65$ & $24 \cdot 17$ & $1 \cdot 07$ & 0.64 \\
\hline Poor diet \& smoking & $7 \cdot 02$ & $241 \cdot 5$ & $1 \cdot 28$ & 0.56 & $22 \cdot 39$ & $0 \cdot 29$ & $0 \cdot 13$ \\
\hline Poor diet, inactive \& overweight & $11 \cdot 69$ & $236 \cdot 2$ & $3 \cdot 44$ & $1 \cdot 78$ & $26 \cdot 59$ & 0.91 & 0.47 \\
\hline Poor diet, inactive \& smoking & $4 \cdot 03$ & $249 \cdot 8$ & $1 \cdot 23$ & 0.53 & $22 \cdot 46$ & $0 \cdot 28$ & $0 \cdot 12$ \\
\hline Poor diet, overweight \& smoking & $9 \cdot 58$ & $248 \cdot 8$ & $1 \cdot 16$ & 0.49 & $26 \cdot 90$ & $0 \cdot 31$ & $0 \cdot 13$ \\
\hline $\begin{array}{l}\text { Poor diet, overweight, inactive \& } \\
\text { smoking }\end{array}$ & $9 \cdot 38$ & $258 \cdot 2$ & $1 \cdot 14$ & $0 \cdot 48$ & $23 \cdot 92$ & $0 \cdot 27$ & $0 \cdot 11$ \\
\hline No modifiable risk factor & $5 \cdot 71$ & $188 \cdot 1$ & 0.00 & $4 \cdot 72$ & $21 \cdot 94$ & 0.00 & 1.04 \\
\hline Inactive & $2 \cdot 38$ & $227 \cdot 0$ & 0.00 & $2 \cdot 99$ & $27 \cdot 64$ & 0.00 & $0 \cdot 83$ \\
\hline Overweight & $6 \cdot 84$ & $233 \cdot 8$ & 0.00 & $2 \cdot 38$ & $27 \cdot 89$ & 0.00 & 0.67 \\
\hline Smoking & $4 \cdot 24$ & $197 \cdot 8$ & 0.00 & $0 \cdot 28$ & $24 \cdot 98$ & 0.00 & 0.07 \\
\hline Inactive \& overweight & $4 \cdot 40$ & $226 \cdot 5$ & 0.00 & $1 \cdot 40$ & $23 \cdot 96$ & 0.00 & 0.33 \\
\hline Smoking \& inactive & $1 \cdot 28$ & $152 \cdot 2$ & 0.00 & 0.08 & $19 \cdot 99$ & 0.00 & 0.02 \\
\hline Smoking \& overweight & $4 \cdot 89$ & $243 \cdot 2$ & 0.00 & 0.44 & $27 \cdot 48$ & 0.00 & $0 \cdot 12$ \\
\hline Smoking, inactive \& overweight & $2 \cdot 36$ & $228 \cdot 9$ & 0.00 & 0.33 & $25 \cdot 01$ & 0.00 & 0.08 \\
\hline Average & & $227 \cdot 7$ & $1 \cdot 5$ & $1 \cdot 9$ & $24 \cdot 8 t$ & $0 \cdot 4$ & 0.5 \\
\hline
\end{tabular}

*Total weighted $n$ is 77129836 ( $\sim 82 \%$ of US females in the National Health and Nutrition Examination Survey 1999-2002).

tBased on weighted individual estimates.

provide some explanation for the lack of findings of an association between dietary cholesterol and $\mathrm{CHD}^{(20)}$. Epidemiological studies also show a very limited effect of cholesterol intake on plasma lipoprotein, while PUFA and SFA intakes are found to closely relate to plasma lipoprotein concentrations ${ }^{(1)}$.

In the NHS, an association between dietary cholesterol and CHD risk was observed, but the relationship was not statistically significant $(P$ for trend $=0 \cdot 24$ ). Nevertheless, assuming that the observed relationship was true and applying the RR associated with dietary cholesterol from the NHS to US females aged 25 years or older, the CHD risk share of current dietary cholesterol is $1.5 \%$ (upperbound estimate: $1.9 \%$ ), as compared with the $2.5 \%$ share from current intake of trans fat (as a percentage of total energy) and the $16 \%$ share from current deficiency in heart-healthy nutrients such as marine $n-3$ FA, PUFA, ALA, dietary fibre, vitamins $\mathrm{B}_{6}$ and $\mathrm{C}$, and folate. These results suggest that while reducing trans fat and cholesterol intake could lead to CHD risk reduction, a greater reduction of CHD risk may be achieved with improving intakes of currently deficient heart-healthy nutrients. Thus, consideration of total diet is essential in evaluating CHD risk reduction strategies.

Egg foods contributed between $20 \%$ and $28 \%$ of the total dietary cholesterol, corresponding to $0 \cdot 4-0 \cdot 5 \%$ of CHD risk among US females $(0.8 \%$ in females with poor diet). It should be noted that published studies do not find any association between CHD and egg consumption $^{(3)}$. The public health significance of egg consumption should be examined in the context of its benefits, since one single, large egg supplies $12 \%$ of the daily value for protein and other nutrients, including vitamins $A, B_{6}, B_{12}$,
$\mathrm{D}$, folate, Fe, $\mathrm{P}$ and $\mathrm{Zn}$. Beneficial effects have also been attributed to functional contents in egg yolk, i.e. choline, lutein and zeaxanthin.

The present study did not model CHD risk shares attributed to dietary factors for US adult males because data from the HPFS did not show any statistically significant association between specific dietary factors and CHD risk, with the exception of dietary and cereal fibres, Fe and alcohol consumption. The data for males from the HPFS are summarized in the Appendix.

There are several key limitations with the findings from the present study. A major consideration concerning the risk apportionment model is the selection of risk factors and estimated RR. Different risk shares may have been derived if dietary factors other than the ten considered were included or if RR from other cohorts were used, e.g. populations with different education levels or without the health knowledge of NHS participants. The associations between CHD and glycaemic load score and vegetable oil intake were statistically significant in the NHS but were not incorporated in the present study. Vegetable oil intakes were not extractable from the NHANES data and the lack of a consistent method to replicate the glycaemic load score were reasons for their exclusion. Both $\alpha$ - and $\beta$-carotene were found to be associated with CHD in the NHS; however, because of the controversy about potential cancer effects, they were not incorporated in the model. Further, since SFA was not included in the model (not shown to be associated with CHD in the NHS), the risk shares of the ten diet factors studied could have been overestimated. If RR for SFA were $>1$ and incorporated, the $\mathrm{CHD}$ risk shares for the ten factors included here would be lowered. 
Moreover, the RR estimates from the NHS were based on consumption data collected using an FFQ. Random and systematic errors are present in FFQ-derived intake estimates, with random error resulting in an attenuation of the RR estimates and systematic error (from under- or over-reporting by consumers) leading to overestimation of the RR. The effect of random variation is typically larger than that of systematic error; however, when multiple factors are included the estimated effect could be biased in either direction ${ }^{(21)}$.

In conclusion, while the NHS was considered the best option for the risk apportionment model because it is a large study with long-follow-up periods and carefully collected information, and the RR estimates were multivariate-adjusted, application of the NHS data in a risk apportionment model is not without limitations. Interpretation of findings from the present study should be made in the context of the underlying data and overinterpretation should be avoided.

\section{Acknowledgements}

The work was partially funded by Exponent and the Egg Nutrition Center. There are no conflicts of interest. N.T. developed and implemented the dietary apportionment model, reviewed and extracted data from the published literature, and prepared and revised the manuscript. L.B. developed the apportionment model, reviewed and extracted data from the published literature, and assisted with manuscript preparation. We appreciate Donald McNamara for his advice and comments, Carolyn Scrafford and Xiaoyu Bi for their assistance.

\section{References}

1. Howell WH, McNamara DJ, Tosca MA, Smith BT \& Gaines JA (1997) Plasma lipid and lipoprotein responses to dietary fat and cholesterol: a meta-analysis. Am J Clin Nutr 65, $1747-1764$

2. Hu FB, Stampfer MJ, Manson JE, Rimm E, Colditz GA, Rosner BA, Hennekens CH \& Willett WC (1997) Dietary fat intake and the risk of coronary heart disease in women. N Engl J Med 337, 1491-1499.

3. Kritchevsky SB \& Kritchevsky D (2000) Egg consumption and coronary heart disease: an epidemiologic overview. J Am Coll Nutr 19, 5 Suppl., 549S-555S.

4. Song WO \& Kerver JM (2000) Nutritional contribution of eggs to American diets. J Am Coll Nutr 19, 5 Suppl., $556 \mathrm{~S}-562 \mathrm{~S}$

5. Barraj LM, Tran NL, Goodman M \& Ginevan ME (2008) Perspective: risk apportionment and disease intervention strategies. Risk Anal 28, 477-486.
6. Centers for Disease Control and Prevention, National Center of Health Statistics (2008) National Health and Nutrition Examination Survey, Data Sets and Related Documentation. NHANES 1999-2000 and NHANES 2001-2002. http://www.cdc.gov/nchs/about/major/nhanes/ datalink.htm (accessed March 2008).

7. Stampfer MJ, Hu FB, Manson JE, Rimm EB \& Willett WC (2000) Primary prevention of coronary heart disease in women through diet and lifestyle. $N$ Engl $J$ Med 343, 16-22.

8. US Department of Agriculture, Agricultural Research Service (2006) USDA National Nutrient Database for Standard Reference, Release 19. http://www.ars.usda.gov/ $\mathrm{ba} / \mathrm{bhnrc} / \mathrm{ndl}$ (accessed March 2008).

9. US Department of Agriculture/Environmental Protection Agency (1998) Continuing Survey of Food Intakes by Individuals (CSFII) 1994-96. http://www.ars.usda.gov/ Services/docs.htm?docid=14514 (accessed March 2008).

10. Oh K, Hu FB, Manson JE, Stampfer MJ \& Willett WC (2005) Dietary fat intake and risk of coronary heart disease in women: 20 years of follow-up of the Nurses' Health Study. Am J Epidemiol 161, 672-679.

11. American Heart Association (2008) Cholesterol. http:// www. americanheart.org/presenter.jhtml?identifier $=4488$ (accessed March 2008).

12. Hu FB, Bronner L, Willett WC, Stampfer MJ, Rexrode KM, Albert CM, Hunter D \& Manson JE (2002) Fish and omega-3 fatty acid intake and risk of coronary heart disease in women. JAMA 287, 1815-1821.

13. Rimm EB, Willett WC, Hu FB, Sampson L, Colditz GA, Manson JE, Hennekens C \& Stampfer MJ (1998) Folate and vitamin $\mathrm{B}_{6}$ from diet and supplements in relation to risk of coronary heart disease among women. JAMA 279, 359-364.

14. Wolk A, Manson JE, Stampfer MJ, Colditz GA, Hu FB, Speizer FE, Hennekens CH \& Willett WC (1999) Long-term intake of dietary fiber and decreased risk of coronary heart disease among women. JAMA 281, 1998-2004.

15. Hu FB, Stampfer MJ, Mason JE, Rimm EB, Wolk A, Golditz GA, Hennekens CH \& Willett WC (1999) Dietary intake of $\alpha$-linolenic acid and risk of fatal ischemic heart disease among women. Am J Clin Nutr 69, 890-897.

16. Osganian SK, Stampfer MJ, Rimm E, Spiegelman D, Hu FB, Manson JE \& Willett WC (2003) Vitamin C and risk of coronary heart disease in women. J Am Coll Cardiol 42, 246-252.

17. Hu FB, Rimm EB, Stampfer MJ, Ascherio A, Spiegelman D \& Willett WC (2000) Prospective study of major dietary patterns and risk of coronary heart disease in men. $A m J$ Clin Nutr 72, 912-921.

18. Kratz M (2005) Dietary cholesterol, atherosclerosis and coronary heart disease. Handb Exp Pharmacol 170, 195-213.

19. Hu FB, Stampfer MJ, Manson JE et al. (1999) Egg consumption and risk of cardiovascular disease in women. Circulation 99, 1109-1121.

20. McNamara DJ (2000) The impact of egg limitations on coronary heart disease risk: do the numbers add up? J Am Coll Nutr 19, 5 Suppl., 540S-548S.

21. Thiébaut AC, Freedman LS, Carroll RJ \& Kipnis V (2007) Is it necessary to correct for measurement error in nutritional epidemiology? Ann Intern Med 146, 65-67. 


\section{Appendix}

Estimated relative risks for dietary factors from the Nurses' Health Study and the Health Professionals' Follow-up Study

Estimated relative risks (RR) for the dietary risk factors (cholesterol, SFA, etc.) were derived from the Nurses' Health Study (NHS). The following publications were found and reviewed: three publications examined the impact of 'total' diet on CHD risk, four evaluated the impact of 'whole foods' on CHD risk, and twelve assessed the impact of specific macro/micronutrients, fats, cholesterol, etc. on CHD risk. Specifically, $\mathrm{Hu}$ et $a l^{(1)}$ and Fung et al. ${ }^{(2)}$ showed that the 'prudent' diet was associated with a lower CHD risk. Stampfer et al. ${ }^{(3)}$ used a diet score to assess diet quality and found that a high diet score was associated with lower CHD risk. Of the four publications that examined the association between 'whole foods' and CHD risk using data from the NHS, two studies $^{(4,5)}$ found no association between coffee or egg consumption and CHD. The other two studies found an inverse association between CHD and intake of fruits and vegetables, green leafy vegetables, vitamin-C-rich fruits and vegetables, and nuts ${ }^{(6,7)}$. A large number of studies $^{(8-27)}$ examined the association between several macro- and micronutrients, fats, cholesterol intakes and $\mathrm{CHD}$ risk. The estimated $\mathrm{RR}$ and the quintiles of intakes for most of these studies are summarized in Table A1.

The present study did not model the share of CHD risk attributed to dietary cholesterol and other dietary risk factors for US adult males because data from the Health Professionals' Follow-up Study (HPFS) did not show any statistically significant association between specific dietary factors and CHD risk, with the exception of dietary and cereal fibres, Fe and alcohol consumption (Table A2). Among the males in the HPFS, a slight increase in CHD risk in the upper (5th) quintile of trans fat intake was observed; however, the relationship is not statistically

Table A1 Specific dietary risk factors and relative risks (RR) from the Nurses' Health Study

\begin{tabular}{|c|c|c|c|c|c|c|c|}
\hline \multirow[b]{2}{*}{ Dietary factor } & \multicolumn{5}{|c|}{ Quintile of intake } & \multirow[b]{2}{*}{$P$} & \multirow[b]{2}{*}{ Reference (outcome) } \\
\hline & 1 & 2 & 3 & 4 & 5 & & \\
\hline$\alpha$-Linolenic acid $(\mathrm{g} / \mathrm{d})$ & $0 \cdot 71$ & 0.86 & 0.98 & $1 \cdot 12$ & $1 \cdot 36$ & 0.5 & Hu et al. $(1999)^{(5)}$ \\
\hline $\mathrm{RR}$ & $1 \cdot 18$ & $1 \cdot 08$ & $1 \cdot 11$ & $1 \cdot 20$ & $1 \cdot 00$ & & (IHD, not CHD, non fatal) \\
\hline SFA $12: 0$ to $18: 0$ (\% of energy) & $9 \cdot 5$ & $11 \cdot 4$ & $12 \cdot 8$ & $14 \cdot 5$ & $17 \cdot 2$ & $0 \cdot 47$ & $\mathrm{Hu}$ et al. $(1999)^{(5)}$ \\
\hline $\mathrm{RR}$ & $1 \cdot 00$ & 0.82 & 0.87 & $1 \cdot 05$ & $1 \cdot 04$ & & (IHD, not CHD, non fatal) \\
\hline Marine $n-3$ fatty acids $(\mathrm{g} / \mathrm{d})$ & 0.03 & 0.05 & 0.08 & $0 \cdot 14$ & $0 \cdot 24$ & $<0.01^{*}$ & $\mathrm{Hu}$ et al. $(2002)^{(12)}$ \\
\hline RR & $1 \cdot 45$ & $1 \cdot 35$ & $1 \cdot 14$ & $1 \cdot 00$ & 1.00 & & (fatal + non fatal CHD) \\
\hline Vegetable fat (\% of energy) & $5 \cdot 4$ & $8 \cdot 8$ & $11 \cdot 2$ & $13 \cdot 5$ & $17 \cdot 2$ & $0.009^{*}$ & Hu et al. $(1997)^{(8)}$ \\
\hline RR & $1 \cdot 00$ & 0.82 & 0.96 & 0.82 & 0.67 & & (fatal + non fatal CHD) \\
\hline Cholesterol (mg/d) & 132 & 163 & 188 & 217 & 273 & $0 \cdot 24$ & Hu et al. $(1997)^{(8)}$ \\
\hline $\mathrm{RR}$ & $1 \cdot 00$ & $1 \cdot 15$ & $1 \cdot 08$ & $1 \cdot 24$ & $1 \cdot 17$ & & (fatal + non fatal CHD) \\
\hline Trans fat (\% of energy) & $1 \cdot 3$ & $1 \cdot 6$ & $1 \cdot 9$ & $2 \cdot 2$ & $2 \cdot 8$ & $0 \cdot 01^{*}$ & Oh et al. $(2005)^{(13)}$ \\
\hline RR & $1 \cdot 00$ & $1 \cdot 08$ & $1 \cdot 29$ & $1 \cdot 19$ & $1 \cdot 33$ & & (fatal + non fatal CHD) \\
\hline PUFA (\% of energy) & $4 \cdot 1$ & $5 \cdot 0$ & $5 \cdot 6$ & $6 \cdot 3$ & $7 \cdot 4$ & $0.004^{*}$ & Oh et al. $(2005)^{(13)}$ \\
\hline RR & $1 \cdot 33$ & $1 \cdot 31$ & $1 \cdot 11$ & $1 \cdot 12$ & $1 \cdot 00$ & & (fatal + non fatal CHD) \\
\hline MUFA (\% of energy) & $10 \cdot 6$ & $12 \cdot 5$ & $13 \cdot 8$ & $15 \cdot 3$ & $18 \cdot 0$ & 0.19 & Oh et al. $(2005)^{(13)}$ \\
\hline RR & $1 \cdot 22$ & $1 \cdot 15$ & $1 \cdot 16$ & $1 \cdot 11$ & $1 \cdot 00$ & & (fatal + non fatal CHD) \\
\hline SFA (\% of energy) & $10 \cdot 1$ & $11 \cdot 9$ & $13 \cdot 3$ & $14 \cdot 8$ & $17 \cdot 6$ & 0.93 & Oh et al. $(2005)^{(13)}$ \\
\hline $\mathrm{RR}$ & $1 \cdot 00$ & 0.94 & 0.96 & $1 \cdot 01$ & 0.97 & & (fatal + non fatal CHD) \\
\hline Total fat (\% of energy) & $28 \cdot 3$ & $32 \cdot 6$ & $35 \cdot 6$ & $38 \cdot 7$ & $44 \cdot 0$ & 0.49 & Oh et al. $(2005)^{(13)}$ \\
\hline RR & $1 \cdot 00$ & 0.94 & 0.91 & 0.98 & 0.92 & & (fatal + non fatal CHD) \\
\hline Vitamin C (mg/d) & 61 & 94 & 121 & 152 & 209 & 0.52 & Osganian et al. $(2003)^{(14,15)}$ \\
\hline RR & $1 \cdot 16$ & $1 \cdot 06$ & $1 \cdot 00$ & 0.98 & $1 \cdot 00$ & & (fatal + non fatal CHD) \\
\hline Lutein \& zeaxanthin $(\mu \mathrm{g} / \mathrm{d})$ & 1194 & 2099 & 2897 & 3938 & 6316 & 0.42 & Osganian et al. $(2003)^{(14,15)}$ \\
\hline RR & $1 \cdot 11$ & 1.00 & 0.90 & 0.87 & $1 \cdot 00$ & & (fatal + non fatal CHD) \\
\hline$\beta$-Carotene $(\mu \mathrm{g} / \mathrm{d})$ & 1720 & 2633 & 3528 & 4843 & 7639 & $0.05^{\star}$ & Osganian et al. $(2003)^{(14,15)}$ \\
\hline $\mathrm{RR}$ & $1 \cdot 35$ & $1 \cdot 20$ & 0.93 & $1 \cdot 20$ & $1 \cdot 00$ & & (fatal + non fatal CHD) \\
\hline$\alpha$-Carotene $(\mu \mathrm{g} / \mathrm{d})$ & 209 & 341 & 456 & 711 & 1518 & $0 \cdot 04^{*}$ & Osganian et al. (2003) $(14,15)$ \\
\hline RR & $1 \cdot 25$ & $1 \cdot 16$ & $1 \cdot 14$ & $1 \cdot 00$ & $1 \cdot 00$ & & (fatal + non fatal CHD) \\
\hline Vitamin E (IU/d) & $2 \cdot 6$ & $3 \cdot 6$ & $4 \cdot 4$ & $5 \cdot 4$ & $7 \cdot 7$ & 0.99 & Stampfer et al. (1993) ${ }^{(17)}$ \\
\hline $\mathrm{RR}$ & $1 \cdot 00$ & $1 \cdot 04$ & 0.87 & $1 \cdot 14$ & 0.95 & & (fatal + non fatal + bypass) \\
\hline Cereal fibre (g/d, energy-adjusted) & $2 \cdot 2$ & $3 \cdot 1$ & $3 \cdot 8$ & $4 \cdot 9$ & $7 \cdot 7$ & $<0 \cdot 01^{*}$ & Wolk et al. $(1999)^{(19)}$ \\
\hline RR & $1 \cdot 52$ & $1 \cdot 61$ & $1 \cdot 08$ & $1 \cdot 15$ & $1 \cdot 00$ & & (fatal + non fatal CHD) \\
\hline Dietary fibre ( $\mathrm{g} / \mathrm{d}$, energy-adjusted) & $11 \cdot 5$ & $14 \cdot 3$ & $16 \cdot 4$ & $18 \cdot 8$ & $22 \cdot 9$ & 0.07 & Wolk et al. $(1999)^{(19)}$ \\
\hline RR & $1 \cdot 30$ & $1 \cdot 27$ & $1 \cdot 19$ & $1 \cdot 13$ & $1 \cdot 00$ & & (fatal + non fatal CHD) \\
\hline Folate $(\mu \mathrm{g} / \mathrm{d})$ & 158 & 217 & 276 & 393 & 696 & $0.003^{*}$ & Rimm et al. $(1998)^{(16)^{\prime}}$ \\
\hline RR & $1 \cdot 45$ & $1 \cdot 25$ & $1 \cdot 25$ & $1 \cdot 13$ & $1 \cdot 00$ & & (fatal + non fatal CHD) \\
\hline Vitamin $\mathrm{B}_{6}(\mathrm{mg} / \mathrm{d})$ & $1 \cdot 1$ & $1 \cdot 3$ & $1 \cdot 7$ & $2 \cdot 7$ & $4 \cdot 4$ & $0 \cdot 002^{*}$ & Rimm et al. $(1998)^{(16)^{\prime}}$ \\
\hline $\mathrm{RR}$ & $1 \cdot 49$ & $1 \cdot 37$ & $1 \cdot 28$ & $1 \cdot 31$ & $1 \cdot 00$ & & (fatal + non fatal CHD) \\
\hline Glycaemic load score (energy-adjusted) & 117 & 145 & 161 & 177 & 206 & $<0.0001^{*}$ & Liu et al. $(2001)^{(27)}$ \\
\hline $\mathrm{RR}$ & $1 \cdot 00$ & $1 \cdot 01$ & $1 \cdot 25$ & $1 \cdot 51$ & 1.98 & & (fatal + non fatal CHD) \\
\hline
\end{tabular}

*Statistically significant. 
Table A2 Dietary risk factors and multivariate-adjusted relative risks (RR) from the Health Professionals' Follow-up Study, adult males

\begin{tabular}{|c|c|c|c|c|c|c|c|}
\hline \multirow[b]{2}{*}{ Dietary factor } & \multicolumn{5}{|c|}{ Quintile of intake } & \multirow[b]{2}{*}{$P$} & \multirow[b]{2}{*}{ Reference (outcome) } \\
\hline & 1 & 2 & 3 & 4 & 5 & & \\
\hline Marine $n-3$ fatty acids $(\mathrm{g} / \mathrm{d})$ & $0 \cdot 07$ & $0 \cdot 15$ & $0 \cdot 24$ & $0 \cdot 34$ & 0.58 & $0 \cdot 48$ & Ascherio et al. (1995) \\
\hline RR & $1 \cdot 00$ & $1 \cdot 00$ & 0.92 & $0 \cdot 86$ & 1.09 & & (fatal + non-fatal CHD) \\
\hline Cholesterol (mg/d) & 189 & 246 & 290 & 338 & 422 & 0.48 & Ascherio et al. (1996) \\
\hline RR & $1 \cdot 00$ & $0 \cdot 86$ & 0.98 & 0.94 & $1 \cdot 03$ & & (fatal + non-fatal CHD) \\
\hline Trans fat $(\mathrm{g} / \mathrm{d})$ & $1 \cdot 5$ & $2 \cdot 2$ & $2 \cdot 7$ & $3 \cdot 3$ & $4 \cdot 3$ & 0.2 & Ascherio et al. (1996) \\
\hline $\mathrm{RR}$ & $1 \cdot 00$ & $1 \cdot 12$ & $1 \cdot 12$ & $1 \cdot 12$ & $1 \cdot 21$ & & (fatal + non-fatal CHD) \\
\hline SFA (g) & 17 & 21 & 24 & 27 & 33 & $0 \cdot 69$ & Ascherio et al. (1996) \\
\hline RR & $1 \cdot 00$ & $1 \cdot 01$ & 0.84 & 0.90 & 0.96 & & (fatal + non-fatal CHD) \\
\hline Total fat $(\mathrm{g} / \mathrm{d})$ & 53 & 64 & 72 & 78 & 89 & 0.42 & Ascherio et al. (1996) \\
\hline $\mathrm{RR}$ & $1 \cdot 00$ & $1 \cdot 00$ & 1.05 & $1 \cdot 07$ & $1 \cdot 02$ & & (fatal + non-fatal CHD) \\
\hline Linoleic acid $(\mathrm{g} / \mathrm{d})$ & $7 \cdot 6$ & $9 \cdot 6$ & 11 & $12 \cdot 6$ & $15 \cdot 4$ & $0 \cdot 89$ & Ascherio et al. (1996) \\
\hline RR & $1 \cdot 00$ & $1 \cdot 21$ & $1 \cdot 12$ & $1 \cdot 10$ & $1 \cdot 04$ & & (fatal + non-fatal CHD) \\
\hline$\alpha$-Linolenic acid $(\mathrm{g} / \mathrm{d})$ & $0 \cdot 8$ & $0 \cdot 9$ & $1 \cdot 1$ & $1 \cdot 2$ & 1.5 & 0.07 & Ascherio et al. (1996) \\
\hline RR & $1 \cdot 00$ & 1.00 & 0.97 & 0.98 & $0 \cdot 8$ & & (fatal + non-fatal CHD) \\
\hline $\mathrm{Fe}$ (mg/d, energy-adjusted) & 11 & 13 & 15 & 18 & 37 & $0 \cdot 02^{*}$ & Ascherio et al. (1994) \\
\hline $\mathrm{RR}$ & $1 \cdot 39$ & $1 \cdot 54$ & 1.53 & $1 \cdot 31$ & 1.00 & & (fatal + non-fatal CHD) \\
\hline $\operatorname{Mg}(\mathrm{mg} / \mathrm{d})$ & 264 & 305 & 336 & 371 & 427 & $0 \cdot 19$ & Al-Delaimy et al. $(2004)^{(23)}$ \\
\hline $\mathrm{RR}$ & $1 \cdot 16$ & $1 \cdot 17$ & $1 \cdot 08$ & 1.06 & $1 \cdot 00$ & & (fatal + non-fatal CHD) \\
\hline Vitamin C $(\mathrm{mg} / \mathrm{d})$ & 92 & 149 & 218 & 392 & 1162 & 0.98 & Rimm et al. $(1993)^{(24)^{\prime}}$ \\
\hline $\mathrm{RR}$ & $1 \cdot 00$ & $1 \cdot 08$ & $1 \cdot 32$ & $1 \cdot 26$ & $1 \cdot 25$ & & (fatal + non-fatal CHD + bypass) \\
\hline Vitamin E (IU) & $4 \cdot 3$ & $7 \cdot 6$ & $8 \cdot 8$ & $10 \cdot 2$ & $11 \cdot 1$ & $0 \cdot 11$ & Rimm et al. (1993) \\
\hline $\mathrm{RR}$ & $1 \cdot 27$ & $1 \cdot 39$ & $1 \cdot 61$ & $1 \cdot 23$ & 1.00 & & (fatal + non-fatal CHD + bypass) \\
\hline Cereal fibre (g/d, energy-adjusted) & $2 \cdot 2$ & $3 \cdot 7$ & $5 \cdot 0$ & $6 \cdot 8$ & $9 \cdot 7$ & $0 \cdot 01^{*}$ & Rimm et al. $(1993)^{(24)}$ \\
\hline RR & $1 \cdot 00$ & 0.96 & $0 \cdot 88$ & $0 \cdot 86$ & $0 \cdot 71$ & & (fatal + non-fatal CHD + bypass) \\
\hline Dietary fibre ( $\mathrm{g} / \mathrm{d}$, energy-adjusted) & $12 \cdot 4$ & $16 \cdot 6$ & $19 \cdot 6$ & $23 \cdot 0$ & $28 \cdot 9$ & $0.004^{*}$ & Rimm et al. (1993) \\
\hline RR & $1 \cdot 56$ & 1.58 & $1 \cdot 50$ & $1 \cdot 44$ & 1.00 & & (fatal + non-fatal CHD + bypass) \\
\hline Alcohol (g/d) & 0 & $2 \cdot 50$ & $9 \cdot 95$ & $22 \cdot 45$ & $40 \cdot 00$ & $0 \cdot 04^{*}$ & $\begin{array}{l}\text { Mukamal et al. }(2003)^{(25)} \\
\text { Mukamal et al. }(2006)^{(26)}\end{array}$ \\
\hline RR & $1 \cdot 00$ & 0.92 & 0.52 & $0 \cdot 32$ & $0 \cdot 70$ & & (fatal + non-fatal CHD) \\
\hline
\end{tabular}

${ }^{*}$ Statistically significant.

significant $(P$ for trend $=0 \cdot 2)$. Non-statistically significant inverse associations between intakes of $\alpha$-linolenic acid, $\mathrm{Mg}$ and vitamin $\mathrm{E}$ and CHD were also observed. In particular, no association between CHD and any of the quintiles of dietary cholesterol, total fat, SFA and marine $n$-3 fatty acids was found among the HPFS subjects. The multivariate-adjusted RR estimates were approximately unity even at the highest (5th) quintile of intake (Table A2). Incorporating dietary factors with $\mathrm{RR}$ of 1 into the apportionment model would apportion $0 \%$ share of the CHD risk for these factors. Based on these results, it would appear that diet and dietary fats do not seem to have a significant impact on CHD risk in adult males.

\section{References}

1. Hu FB, Rimm EB, Stampfer MJ, Ascherio A, Spiegelman D \& Willett WC (2000) Prospective study of major dietary patterns and risk of coronary heart disease in men. $\mathrm{Am} \mathrm{J}$ Clin Nutr 72, 912-921.

2. Fung TT, Willett WC, Stampfer MJ, Manson JE \& Hu FB (2001) Dietary patterns and the risk of heart disease in women. Arch Intern Med 161, 1857-1862.

3. Stampfer MJ, Hu FB, Manson JE, Rimm EB \& Willett WC (2000) Primary prevention of coronary heart disease in women through diet and lifestyle. $N$ Engl J Med 343, $16-22$.

4. Lopez-Garcia E, van Dam RM, Willett WC, Rimm ER, Manson JE, Stampfer MJ, Rexrode KM \& Hu FB (2006) Coffee consumption and coronary heart disease in men and women: a prospective cohort study. Circulation 113, 2045-2053.

5. Hu FB, Stampfer MJ, Manson JE et al. (1999) Egg consumption and risk of cardiovascular disease in women. Circulation 99, 1109-1121.

6. Joshipura KJ, Hu FB, Manson JE et al. (2001) The effect of fruit and vegetable intake on risk for coronary heart disease. Ann Intern Med 134, 1106-1114.

7. Hu FB, Stampfer MJ, Manson JE, Rimm EB, Colditz GA, Rosner BA, Speizer FE, Hennekens CH \& Willett WC (1998) Frequent nut consumption and risk of coronary heart disease in women: prospective cohort study. BMJ 317, $1341-1345$

8. Hu FB, Stampfer MJ, Manson JE, Rimm E, Colditz GA, Rosner BA, Hennekens CH \& Willett WC (1997) Dietary fat intake and the risk of coronary heart disease in women. $N$ Engl J Med 337, 1491-1499.

9. Halton TL, Willett WC, Liu S, Manson JE, Albert CM, Rexrode K \& Hu FB (2006) Low-carbohydrate-diet score and the risk of coronary heart disease in women. $N$ Engl J Med 355, 1991-2002.

10. Hu FB, Stampfer MJ, Manson JE, Ascherio A, Colditz GA, Speizer FE, Hennekens CH \& Willett WC (1999) Dietary saturated fats and their food sources in relation to the risk of coronary heart disease in women. Am J Clin Nutr $\mathbf{7 0}$, 1001-1008.

11. Hu FB, Stampfer MJ, Mason JE, Rimm EB, Wolk A, Golditz GA, Hennekens CH \& Willett WC (1999) Dietary intake of $\alpha$-linolenic acid and risk of fatal ischemic heart disease among women. Am J Clin Nutr 69, 890-897.

12. Hu FB, Bronner L, Willett WC, Stampfer MJ, Rexrode KM, Albert CM, Hunter D \& Manson JE (2002) Fish and omega-3 fatty acid intake and risk of coronary heart disease in women. JAMA 287, 1815-1821. 
13. Oh K, Hu FB, Manson JE, Stampfer MJ \& Willett WC (2005) Dietary fat intake and risk of coronary heart disease in women: 20 years of follow-up of the Nurses' Health Study. Am J Epidemiol 161, 672-679.

14. Osganian SK, Stampfer MJ, Rimm E, Spiegelman D, Hu FB, Manson JE \& Willett WC (2003) Vitamin C and risk of coronary heart disease in women. $J$ Am Coll Cardiol $\mathbf{4 2}$ 246-252.

15. Osganian SK, Stampfer MJ, Rimm E, Spiegelman D, Manson JE \& Willett WC (2003) Dietary carotenoids and risk of coronary artery disease in women. Am J Clin Nutr 77, 1390-1399.

16. Rimm EB, Willett WC, Hu FB, Sampson L, Colditz GA, Manson JE, Hennekens C \& Stampfer MJ (1998) Folate and vitamin $\mathrm{B}_{6}$ from diet and supplements in relation to risk of coronary heart disease among women. JAMA 279, 359-364.

17. Stampfer MJ, Hennekens $\mathrm{CH}$, Manson JE, Colditz GA, Rosner B \& Willett WC (1993) Vitamin E consumption and the risk of coronary disease in women. $N$ Engl J Med 328, 1444-1449.

18. Tanasescu M, Cho E, Manson JE \& Hu FB (2004) Dietary fat and cholesterol and the risk of cardiovascular disease among women with type 2 diabetes. Am J Clin Nutr 79, 999-1005.

19. Wolk A, Manson JE, Stampfer MJ, Colditz GA, Hu FB, Speizer FE, Hennekens CH \& Willett WC (1999) Long-term intake of dietary fiber and decreased risk of coronary heart disease among women. JAMA 281, 1998-2004.

20. Ascherio A, Rimm EB, Stampfer MJ, Giovannucci EL \& Willett WC (1995) Dietary intake of marine $n$-3 fatty acids, fish intake, and the risk of coronary disease among men. $N$ Engl J Med 332, 977-982.

21. Ascherio A, Rimm EB, Giovannucci EL, Spiegelman D, Stampfer M \& Willett WC (1996) Dietary fat and risk of coronary heart disease in men: cohort follow-up study in the United States. BMJ 313, 84-90.

22. Ascherio A, Willett WC, Rimm EB, Giovannucci EL \& Stampfer MJ (1994) Dietary iron intake and risk of coronary disease among men. Circulation 89, 969-974.

23. Al-Delaimy WK, Rimm EB, Willett WC, Stampfer MJ \& Hu FB (2004) Magnesium intake and risk of coronary heart disease. J Am Coll Nutr 23, 63-70.

24. Rimm EB, Stampfer MJ, Ascherio A \& Giovannucci E (1993) Vitamin E consumption and the risk of coronary heart disease in men. New Engl J Med 328, 1450-1456.

25. Mukamal KJ, Conigrave KM, Mittleman MA, Camargo CA, Stampfer MJ, Willett WC \& Rimm EB (2003) Roles of drinking pattern and type of alcohol consumed in coronary heart disease in men. $N$ Engl J Med 348, 109-118.

26. Mukamal KJ, Chiuve SE \& Rimm EB (2006) Alcohol consumption and risk for coronary heart disease in men with healthy lifestyles. Arch Intern Med 166, $2145-2150$.

27. Liu S, Manson JE, Stampfer MJ, Holmes MD, Hu FB, Hankinson SE \& Willett WC (2001) Dietary glycemic load assessed by food-frequency questionnaire in relation to plasma high-density-lipoprotein cholesterol and fasting plasma triacylglycerols in postmenopausal women. $\mathrm{Am} \mathrm{J}$ Clin Nutr 73, 560-566. 